\section{PESQUISA PEDAGÓGICA EM EDUCAÇÃO FÍSICA E OS "ESTUDOS NOS/DOS/COM OS COTIDIANOS": ENTRE O CONTEXTUALISMO E A TRANSCENDÊNCIA}

\author{
PEDAGOGICAL RESEARCH IN PHYSICAL EDUCATION AND "STUDIES IN/OF/ \\ WITH EVERYDAY LIFE": BETWEEN CONTEXTUALISM AND TRANSCENDENCE
}

INVESTIGACIÓN PEDAGÓGICA EN EDUCACIÓN FÍSICA Y LOS "ESTUDIOS EN/DE/CON LOS COTIDIANOS": ENTRE EL CONTEXTUALISMO Y LA TRASCENDENCIA

Thiago da Silva Machado*, Valter Bracht**
Palavras chave: Educação. Pesquisa. Teoria social. Educação Física.

\begin{abstract}
Resumo: Trata de um estudo teórico que discute a pesquisa pedagógica em Educação Física (EF), problematizando a pertinência da adoção da perspectiva dos "estudos nos/ dos/com os cotidianos" (FERRAÇO, 2007) como artefato teórico-metodológico alternativo às pesquisas clássicas. Destaca positivamente os aspectos metodológicos e 0 tipo de valorização da produção docente preconizada nestas investigações. Considera, frente ao diagnóstico acerca das práticas pedagógicas da EF Escolar, a necessidade de manutenção de um tipo de teorização pedagógica ainda dotada de um referente normativo crítico. Sugere, por fim, a assunção da proposta de "reconstrução normativa" de Axel Honneth (2015), a fim de potencializar a noção de uma "crítica imanente" nas pesquisas pedagógicas da EF.
\end{abstract}

\section{Keywords:}

Physical Education.

Education.

Research.

Social Theory.

Palabras clave: Educación Física.

Educación.

Investigación.

Teoría social.
Abstract: This is a theoretical study that discusses pedagogical research in Physical Education (PE), debating the pertinence of adopting the perspective of "studies in/of/ with everyday life" (FERRAÇO, 2007) as a theoretical and methodological tool alternative to classic research. It positively highlights the methodological aspects and the type of value given to teaching production advocated in these studies. It considers the need to maintain a type of pedagogical theorization still carrying a critical normative reference on the diagnosis about the pedagogical practices of school PE. Finally, it proposes adopting Axel Honneth's (2015) proposal for "normative reconstruction" in order to enhance the notion of an "immanent critique" in PE pedagogical research.

Resumen: Se trata de un estudio teórico que discute la investigación pedagógica en Educación Física (EF), problematizando la pertinencia de la adopción de la perspectiva de los "estudios en/de/con los cotidianos" (FERRAÇO, 2007) como artefacto teórico metodológico alternativo a las investigaciones clásicas. Destacan positivamente los aspectos metodológicos y el tipo de valorización de la producción docente preconizada en estas investigaciones. Se considera, frente al diagnóstico acerca de las prácticas pedagógicas de la EF escolar, la necesidad de mantener un tipo de teorización pedagógica aún dotada de un referente normativo crítico. Sugiere, por fin, la asunción de la propuesta de "reconstrucción normativa" de Axel Honneth (2015), a fin de potenciar la noción de una "crítica inmanente" en las investigaciones pedagógicas de la EF.
${ }^{*}$ Católica de Vitória - Centro Universitário. Vitória, ES, Brasil. E-mail: thiago.m_ef@hotmail.com

**Universidade Federal do Espírito Santo. Vitória, ES, Brasil. E-mail: vbracht13@gmail.com

Recebido em: 30-11-2017 Aprovado em: 31-01-2018

DOI: http://dx.doi.org/10.22456/1982-8918.78334 (c) (1) (8) Licence 


\section{INTRODUÇÃOO}

Seja no campo educacional mais amplo, seja no campo específico da Educação Física (EF), por meio de uma análise em retrospectiva, observamos uma reformulação teóricometodológica no plano das chamadas "pesquisas pedagógicas". No caso da EF, evidenciamos que, para além do deslocamento de uma ênfase em estudos com caráter de fundamentação para aqueles preocupados com a intervenção, a própria forma como as categorias de fundamentação e intervenção são interpretadas se alterou. Esse processo ocorre, entre outros motivos, em função da diversidade de referenciais incorporados à area nos últimos 25-30 anos. Assim, muito em função do diálogo estabelecido com o campo mais amplo da Educação, a partir dos anos 2000, uma multiplicidade de "correntes" identificadas/agrupadas em escolas de pensamento como o pós-modernismo, o pós-estruturalismo, os estudos culturais, entre outros, se fazem mais presentes na EF (BRACHT et al., 2012).

A despeito de uma discussão sobre cada uma dessas perspectivas, essa pluralidade de referenciais permitiu aos pesquisadores da EF diversificar as temáticas/objetos de interesse ${ }^{1} \mathrm{e}$, sobretudo, ampliar os modos de compreensão/tratamento daqueles elementos já clássicos da área. A título de ilustração, podem ser citadas: a ressignificação das noções de sujeito e objeto; o maior emprego de métodos de pesquisa colaborativos nas investigações empíricas; as iniciativas de valorização dos contextos/cotidianos como lócus de produção de conhecimento; a redefinição da relação teoria-prática nas pesquisas de fundamentação e intervenção; a secundarização do caráter denunciador/desconstrutivo da pesquisa, em prol de estudos mais descritivos/problematizadores/propositivos, etc. Nesse sentido, se o saldo desse relacionamento nos tem sido favorável, não é de se estranhar a maneira quase natural com que diversas tendências emergentes no campo da pesquisa em Educação são acolhidas pelo campo pedagógico da EF.

Interessa-nos destacar que esse aspecto não se limitou às produções com caráter propositivo ou de fundamentação (da tentativa de definir "o que é" ou "para que serve" a EF Escolar), mas estendeu-se às próprias maneiras de se interpretar as práticas e intervenções que se processam nas instituições de educação básica. Esse é o caso dos mais recentes estudos nos/dos/com os cotidianos (FERRAÇO, 2007)2, perspectiva teórico-metodológica que ganha força no campo educacional brasileiro, e que, de forma progressiva, parece se fazer também presente nas produções da EF Escolar (são exemplos: Nunes; Ferreira Neto (2012); Falcão et al. (2012); Santos; Maximiano (2013)).

No entanto, entendemos que alguns aspectos dessa profícua relação entre os campos de produção de conhecimento da EF e da Educação podem ser problematizados. Nos referimos a ideia de que, diante das peculiaridades da constituição de seu campo, caberia à EF a configuração de uma relação mais autônoma com a produção em Educação, particularmente no contexto atual. Ou seja, os avanços alcançados pela área talvez já nos permitam tanto atuar de forma mais propositiva no debate educacional mais amplo, quanto estabelecer filtros na recepção de tais produções como referenciais para a EF (situação extensiva também às pesquisas nos/dos/com os cotidianos). Assim, a despeito de alguns elementos potentes de

1 Destacam-se, nesse caso, os estudos interessados em temáticas relacionadas à cultura escolar e à epistemologia da prática, além da emergência de temas como multiculturalismo, gênero, diversidade, etc. 
tais estudos para ressignificação de um olhar para o chão da escola, julgamos importante que sua apropriação seja acompanhada de uma espécie de problematização das possibilidades e limitações destes para a pesquisa na EF Escolar (para tanto, particularmente, consideramos os diagnósticos sobre o estado atual da disciplina no contexto dessa educação básica).

Diante dessa situação, no presente texto, após apresentar os pressupostos centrais dos estudos nos/dos/com, buscamos discutir a questão do contextualismo que lhes é inerente. ${ }^{3}$ De forma complementar, construímos um ensaio teórico onde destacamos algumas premissas que embasam a "reconstrução normativa" de Axel Honneth (2015), de maneira a especular acerca das contribuições que a noção de "crítica imanente" dele derivada pode oferecer à pesquisa pedagógica (crítica) em EF.

\section{ESTUDOS NOS/DOS/COM OS COTIDIANOS COMO PERSPECTIVA INVESTIGATIVA E DE PRODUÇÃO DO CONHECIMENTO}

É cada vez maior o número de pesquisadores, grupos de estudos e/ou produções que se dedicam a pensar a Educação sob a ótica dos estudos do cotidiano, entre eles, destacamos os "estudos nos/dos/com os cotidianos". O crescimento dessa corrente de pesquisa, fortemente influenciada pelo próprio desenvolvimento do campo específico de uma sociologia do cotidiano, tem como premissa demonstrar a centralidade dos acontecimentos cotidianos na construção do conhecimento. Para Oliveira e Sgarbi (2008), um ponto de partida fundamental é a constatação óbvia de que o cotidiano "sempre existiu" e que suas "acontecências" permeiam o processo de produção de bens culturais.

Ou seja, aqui, nos referimos ao delineamento de uma perspectiva de pesquisa interessada no plano da intervenção, mas que, no entanto, tem buscado diferenciar-se das tradicionais investigações que dele se ocupam (daí, inclusive, a opção pela adoção de uma nomenclatura própria (FERRAÇO, 2007)). Entendemos que tal diferenciação pode ser observada ao menos em três aspectos mais gerais: na postura política de defesa/aposta no cotidiano; na radicalização de uma epistemologia do cotidiano; e na descontinuidade com as metodologias de pesquisa clássicas. Assim, tais elementos nos permitem interpretar os estudos nos/dos/com os cotidianos como uma corrente investigativa específica dentro da área das pesquisas que têm como foco a intervenção (pois compartilham com essa mesma área o escopo de tematização da prática pedagógica, contudo, estabelecem um modo próprio de operar, interpretar e produzir conhecimento).

A presença dos estudos nos/dos/com os cotidianos no conjunto das produções em Educação já é marcante. Além de uma questão quantitativa, essa afirmação tem como base a própria regularidade com que essas pesquisas se apresentam ao longo dos anos. Somase a isso a percepção de que, paulatinamente, evidencia-se de forma cada vez mais nítida o estabelecimento de um campo ou forma específica de fazer pesquisa (aspecto notado na peculiaridade do vocabulário utilizado, nos referenciais teóricos privilegiados, nas características e formas de operar com métodos e instrumentos de pesquisa, etc.). Outro aspecto concerne à proposta de que essa corrente investigativa, ao apostar na diversidade, tem como uma de suas peculiaridades não se deixar aprisionar em caracterizações definitivas.

3 Discussão desenvolvida a partir de um levantamento realizado nos trabalhos publicados no Grupo de Trabalho Currículo da Anped, entre os anos de 2000 e 2015. Dialogamos, ainda, com outras obras identificadas com tal perspectiva, por exemplo, o livro Aprendizagens cotidianas com a pesquisa: novas reflexões em pesquisa nos/dos/com os cotidianos (FERRAÇO; PEREZ; OLIVEIRA, 2008). 
Em relação à fundamentação, ressaltamos especialmente os usos dos escritos de Michel de Certeau, com destaque para $A$ invenção do cotidiano l: artes de fazer (1994). Ao demonstrar a não passividade dos sujeitos frente às imposições de diversas ordens a que são submetidos, tal obra é interpretada por muitos como um rompimento de duplo caráter: epistemológico e político (aspecto também visualizado nas pesquisas nos/dos/com os cotidianos). ${ }^{4}$ Quer dizer, de acordo com Oliveira (2008, p. 174), a assunção dessa perspectiva representaria uma espécie de reação às proposições que desconsideram os saberes que circulam nas escolas, assim como significa uma busca pela "[...] criação de possibilidades de não apenas explicar os problemas das escolas, suas fraquezas e impossibilidades, mas de compreendê-las nos seus fazeres e naquilo que os tornava possíveis e potencialmente aperfeiçoáveis [...]".

Pensar em diversidade, em 'multi', é conceber os espaços-tempos do conhecimento e da cultura como plurais e, portanto, a não serem hegemonizados um pelo outro. A ideia é polêmica, mas necessária ao debate, na medida em que permite avançar na construção de uma perspectiva de maior respeito pela diversidade de fazeres-saberes docentes e menos formulação de modelos tão inúteis quanto desnecessários do que esses deveriam ser (OLIVEIRA, 2008, p. 29-30).

Desse modo, aponta-se que "[...] o perfil epistemológico das relações sociais não é fornecido por uma forma epistemológica específica, nomeadamente a forma epistemológica mundial (a ciência), mas sim pelas diversas constelações de conhecimentos que as pessoas e os grupos produzem e utilizam" (SANTOS ${ }^{5}$ apud OLIVEIRA; SGARBI, 2008, p. 74-75). Quer dizer, a partir de autores como Boaventura de Souza Santos, Edgar Morin, Giles Deleuze, Michel de Certeau, Carlo Ginzburg e Humberto Maturana, só para citar alguns, a tentativa de traçar os contornos de uma "epistemologia do cotidiano" figura como outro empreendimento importante. Para além, o diálogo com tais referenciais embasa a aposta na revisão dos modos de se entender aqueles elementos que, por assim dizer, se configuraram historicamente como balizadores da forma escolar moderna (as definições de tempo-espaço escolar, currículo, conhecimento, entre outros, teriam seus contornos "borrados", assumindo formas e possibilidades mais múltiplas ou plurais). Consequentemente, vê-se ampliada a maneira como tais estudos compreendem e discutem as práticas pedagógicas, os processos de avaliação e, de maneira geral, a própria função da escola (cujas referências para a construção de boas práticas, assim como para 0 sucesso/insucesso escolar, residiria nas especificidades e dinâmicas dos próprios cotidianos em questão). Nesse ponto se nota a valorização e demarcação de uma perspectiva ampliada ou diferente do entendimento corriqueiro de conhecimento (daí o emprego de expressões como "redes de saberes" ou "saberes-fazeres").

A ideia de "cotidianos" não aprisionáveis em uma única verdade/modelo/teoria leva à impossibilidade de tais estudos assumirem qualquer fechamento, conclusão ou afirmação de certezas epistemológicas (FERRAÇO; PEREZ; OLIVEIRA, 2008). ${ }^{6}$ Assim, a configuração de uma epistemologia do cotidiano, nos termos dos estudos nos/dos/com os cotidianos, não deve ter como preocupação a ideia de traduzir a produção das práticas e saberes escolares por meio de uma sua submissão à códigos/lógicas/normatividades que lhes seriam externas. CaberiaIhes, isso sim, configurar-se numa epistemologia cujo sentido distancia-se do caráter de uma

4 Não se trata de expressarmos a crença na possibilidade de uma epistemologia sem política, mas destacar a intenção política que motiva/ acompanha a empreitada de Certeau.

5 SANTOS, B. S. A crítica da razão indolente: contra o desperdício da experiência. São Paulo: Cortez, 2000. 
sentença conclusiva ou prescritiva (nessa direção, prescindem dos argumentos de autoridade que tudo resolvem) (SGARBI, 2008). Logo, ao qualificar o cotidiano como uma espécie de "devir" que escapa a todo e qualquer conceito, classificação ou estrutura, as pesquisas nos/ dos/com assumem a necessidade de, mais do que adaptar as metodologias já tradicionais, realizar proposições metodológicas específicas (FERRAÇO, 2008). Entre outros, o uso de narrativas e imagens como recurso de produção de dados, em função da multiplicidade de sentidos que evocam, tem sido apontado como uma estratégia potente.

\section{POTENCIAL DOS ESTUDOS NOS/DOS/COM OS COTIDIANOS FRENTE AO ESTADO ATUAL DA EF ESCOLAR}

Se do ponto de vista das proposições o reconhecimento do caráter aberto/plural das práticas tem se tornado central no campo da EF, o mesmo pode ser visualizado nas pesquisas que buscam compreender a materialização de tais práticas nas escolas. Diante do que foi exposto, insistimos na afirmação de que propostas como a dos emergentes estudos nos/dos/ com os cotidianos podem conter aspectos com potencial para a qualificação da pesquisa pedagógica em EF. Nesse sentido, inspirando-nos naquilo que Nilda Alves (2001; 2002; 2007) tem descrito em suas produções ao ressaltar as contribuições dessas investigações para 0 campo do currículo, destacamos possíveis aspectos para pensar também a pesquisa em EF:

- O fortalecimento da ideia de uma visão de cotidiano que se paute no reconhecimento de outras experiências/produções como também importantes/válidas (aspectos que se vinculam à ideia de tessitura dos conhecimentos e significações em redes como modo de criação nos cotidianos, bem como ao entendimento de que esses conhecimentos criados são necessários para o existir humano, em múltiplos contextos e nos processos educativos variados). Esse modo de olhar para o chão da escola, que considera o diferente como mais uma possibilidade, talvez apresente-se como uma saída plausível para a compreensão das experiências que, situadas no "entre" das classificações comumente empregadas na EF, insistem em escapar dos modelos/obviedades a partir dos quais temos buscado correspondências no cotidiano.

- No destaque ou valorização do potencial contido numa espécie de "não passividade/ aprisionamento" dos docentes e de suas práticas cotidianas aos condicionantes das estruturas (ou seja, daquilo que o resgate das "memórias" dos praticantes permite-nos ressaltar, mormente, em relação aos usos dos artefatos culturais existentes, a partir de múltiplas e complexas táticas, em seus modos de ampliar o consumo). Tal aspecto já fora problematizado no campo da EF por Taborda de Oliveira (2003) ao indagar "o que é feito pelos sujeitos com aquilo que as estruturas deles fazem?" e responder, de forma direta, que eles seguramente reinventam, nos limites das determinações, o seu viver cotidiano.

- A "abertura" para que outras possibilidades metodológicas, mais flexíveis e amplas, sejam criadas (o que se refere aos chamados "movimentos" através dos quais se promoveria maior aproximação das redes educativas tecidas cotidianamente). A esse respeito, diversas tem sido as possibilidades ensaiadas em pesquisas acerca da intervenção na $E F$, principalmente nos modos de interpretar os dados produzidos nas investigações. No entanto, nos estudos nos/dos/com os cotidianos tais possibilidades metodológicas parecem anunciar-se de forma mais inflexora nas diferentes etapas da pesquisa. 
- A construção de modelos compreensivos de pesquisa valorizadores das normatividades e lógicas próprias a partir das quais se organizam e se (re)produzem as culturas escolares. Logo, são privilegiadas interpretações em que os contextos cotidianos, já que complexos, são tomados/analisados como as referências mais centrais para a interpretação dos processos e práticas que nestes se efetivam. Como consequência, delineia-se um exercício de crítica contextual que tem como mote uma maior preocupação em ressaltar aquilo de positivo que se observa no "chão das escolas", e não operar de forma problematizadora.

Se estes são alguns dos aspectos que se apresentam inspiradores para a produção da $\mathrm{EF}$, no entanto, atestar elementos potenciais de tais estudos para a investigação pedagógica da EF não pode significar uma sua absorção direta/completa. Quer dizer, torna-se necessário, antes, problematizá-los à luz da forma específica como a intervenção da EF vem se construindo nas escolas. A questão, nos parece, refere-se a pensarmos em que medida é viável a operação com um modelo de pesquisa que, dada sua aposta (política) num otimismo do cotidiano, tende a radicalizar o caráter autorreferenciado desse mesmo cotidiano nos processos de interpretação das práticas escolares (ou seja, um certo contextualismo). No caso da EF Escolar hodierna, tal situação parece inviabilizada, particularmente, quando notamos, em variados estudos/ diagnósticos acerca das práticas dessa disciplina na escola, o delineamento de um período "entre o não mais e o ainda não" (cujo produto hegemônico ou a manifestação mais evidetende, grosso modo, remete a experiências de um estado de "desinvestimento pedagógico" ou às situações de "não aula") (GONZÁLEZ; FENSTERSEIFER, 2009).

Aqui, não se trata de desconsiderar as experiências positivas na EF Escolar com as quais podemos aprender, e que, portanto, merecem ser compartilhadas. Ou, ainda, de não reconhecermos que as práticas construídas no cotidiano da disciplina, apesar de configuradas por lógicas nem sempre tão óbvias (ou até dissonantes daquilo que a produção do campo vem acumulando), são dotadas de competências formativas/potencializadoras. Tratamos, isso sim, de indagar um tipo de valorização incondicional de tudo o que se produz no chão da escola, dada sua consequência de conduzir a uma situação na qual, aparentemente, torna-se praticamente dispensável a elaboração de critérios a partir dos quais as experiências pedagógicas devem ser problematizadas.

Ou seja, é como se o interesse/reconhecimento na/da riqueza dos saberes advindos da pluralidade das práticas situadas, necessariamente, pressupusesse uma contraposição entre tal pluralidade e a acepção de quaisquer fundamentos que pudessem figurar como referenciais normativos das intervenções escolares. Este é um ponto que se destaca quando nos deparamos com os argumentos acerca de um "devir cotidiano", em que o cotidiano é visto como espaço do efêmero, do imprevisível e do caótico, sendo, portanto, fugidio a quaisquer conceitos e/ou estruturas (logo, e em última instância, dependente dos sujeitos).

Se as dinâmicas cotidianas dependem dos sujeitos, resta saber em que medida seus "processos e produtos" devem ser vistos sempre como positivos. Quer dizer, pensando a partir de Honneth (2003), se as ações e práticas docentes estão atreladas justamente às possibilidades identitárias reconhecidas em um determinado contexto, faz-se pertinente a formulação da hipótese de que também a afirmação ou construção de "saberes-fazeres no/ do cotidiano escolar" estaria sempre mediada pelo alcance de expectativas que adquirem pretensões de validade na comunidade (de valores) escolar em questão. Nessa esteira, o 
pressuposto destacado permite-nos o entendimento de que não se trata de conceber tais saberes como certos/bons ou errados/ruins antecipadamente; tão somente, nos permite reconhecer a dimensão situada das práticas e produções cotidianas em nossos esforços interpretativos. Ou seja, de maneira paradoxal, o elemento teórico destacado, ao mesmo tempo em que corrobora uma valorização de interpretações como as das pesquisas nos/dos/com os cotidianos, também nos alerta para os problemas decorrentes de uma sua naturalização.

Afinal, sendo radicais em nosso argumento, não seria infundado afirmarmos ser sempre possível a construção de uma "justificação" para a existência de contextos/cotidianos cada vez mais "específicos", nos quais as práticas e "produções" (também cada vez mais específicas), se levadas ao extremo, nos impediriam de reconhecer na escola o seu caráter de instituição social pública e democrática. Por exemplo: como interpretar contextos nos quais se configuram práticas que, do ponto de vista dos membros de uma comunidade escolar, são dotadas de valoração positiva, pois atendem as "necessidades mais imediatas" dessa mesma comunidade, mas que, contudo, não podem ser identificadas com o que poderíamos chamar de um "processo educativo formal" cabível ao ambiente escolar??

Assim, se, por um lado, visualizamos nas pesquisas nos/dos/com os cotidianos a potência da ideia de que a diversidade de contextos, culturas e práticas escolares carece de ser compreendida a partir de referentes múltiplos e suficientemente amplos, por outro lado, preocupa-nos o fato de que uma radicalização da crítica ao modelo escolar moderno e de sua fundamentação caracterize também uma espécie de secundarização, no plano da pesquisa, da discussão acerca da construção/adoção de parâmetros (configuradores de um tipo de referencial normativo) que sirvam tanto para orientar as ações/produções docentes no/do cotidiano escolar, quanto constituir o solo comum a partir do qual o diálogo crítico com tais produções possa ser estabelecido. Ou seja, não deve se converter na noção de que qualquer fundamentação (pois prévia ou externa) seria prescindível. Afinal, desse modo, corre-se o risco da perda de qualquer referente de objetividade para a efetivação de um projeto (de EF) escolar mais amplo. ${ }^{8}$

Nessa direção, não nos colocamos contrários à assunção, no plano da pesquisa pedagógica em EF, de perspectivas investigativas como as representadas pelas investigações nos/dos/com os cotidianos. Quer dizer, vemos em tal perspectiva um potencial configurado, particularmente, pelo diagnóstico crítico que aponta em relação à maneira como a tradição de pesquisa educacional, majoritariamente, teria operado em seus esforços por compreender/ orientar as práticas escolares. No entanto, mesmo compartilhando deste diagnóstico crítico, temos dúvidas quanto à pertinência das saídas apresentadas. Esta nossa postura encontra razão, principalmente, no fato de tais alternativas conotarem certa impossibilidade de operação com critérios de análise/proposição que transcendam os contextos cotidianos analisados (configurando, na melhor das hipóteses, uma crítica "fraca"). Ou, ainda, de forma mais radical, por atribuírem a esse empreendimento analítico/propositivo o status de algo quase

\footnotetext{
7 Aqui, lembramos a exposição oral do professor Santiago Pich, num encontro de grupos de pesquisa ocorrido na Universidade Regional do Noroeste do Estado do Rio Grande do Sul (UNIJUÍ), no ano de 2011, ao destacar o que ele chamou de caráter funcional do "desinvestimento pedagógico". Pich apontava um estudo de caso em que a situação de "não aula", configurada na prática do professor de EF, era vista com "bons olhos" pela escola, que enxergava na ação deste professor ou no espaço-tempo desta disciplina uma espécie de "curinga" que permitia flexibilizar a rotina da instituição.

8 Aqui, objetividade lembra que, se a construção do currículo escolar no cotidiano deve, entre outras coisas, respeitar uma dimensão formal/comum (configurada pelos saberes objetivados nas disciplinas escolares, cuja efetivação pressupõe o atendimento a determinada razoabilidade que extrapola os valores/crenças, possibilidades e/ou vontade individual/contextual), também as análises/teorizações acerca da escola devem estar atentas a isso.
} 
desnecessário, pois fundado num "dever-ser" decorrente de uma epistemologia pertencente a um cotidiano [o científico/acadêmico] que, apesar de diferente, é tão cotidiano quanto o escolar - logo, questionável em relação a sua pressuposta superioridade orientadora.

O desafio extraído da reflexão empreendida, portanto, diz respeito à necessidade/ possibilidade de empreendermos uma articulação entre uma teorização pedagógica do cotidiano com características de crítica forte (no sentido de permitir uma sua transcendência) e uma perspectiva que leve em consideração a vinculação de tais práticas a uma normatividade produzida/atualizada no contexto institucional em que se configuram. Conforme aponta Gambarotta (2014, p. 19), o desafio parece ser o de uma elaboração que, do ponto de vista de seu potencial analítico, "[...] ni se funde normativamente ni deje sin fundamentos a la práctica de la crítica". Diante disto, dedicamos os parágrafos finais deste manuscrito à apresentação do projeto de "reconstrução normativa" de Axel Honneth (2015), seguida de breve reflexão acerca de seu potencial para a atualização da pesquisa/teorização pedagógica (ainda crítica!?) da EF.

\section{4 "RECONSTRUÇÃO NORMATIVA" COMO MÉTODO EM AXEL HONNETH E A PESQUISA/TEORIZAÇÃO PEDAGÓGICA EM EF}

Em seus mais recentes trabalhos, Axel Honneth (2009; 2015) dedicou-se também à problemática da construção de uma alternativa metodológica frente à questão das possibilidades e atualidade de uma Teoria Crítica da sociedade na contemporaneidade. Para tanto, levou adiante uma construção teórico-metodológica expressada naquilo que concebe como "reconstrução normativa", da qual deriva a ideia de uma "crítica imanente". Seguindo ao pressuposto básico da argumentação do autor, acreditamos que tal modelo se mostra promissor também para a tentativa de revigoração de uma perspectiva de teoria pedagógica crítica da $E F$, em que a dimensão crítica não se constituiria em algo externo ao objeto criticado (de outro modo, deve ancorar-se, portanto, na compreensão da dimensão normativa subjacente às instituições e das práticas nela efetivadas).

Segundo Honneth (2009), ao seguir os pressupostos marxianos da crítica à ideologia (a saber, de que "os ideais normativos que serviriam para criticar com fundamento a realidade do capitalismo deviam ser localizados na própria realidade social") essa "via reconstrutiva" esteve sempre no horizonte dos teóricos da Escola de Frankfurt, ainda que, para ele, os frankfurtianos tenham falhado em levá-la a cabo. Na visão de Kaupinnen, citado por Caux (2015, p. 84), ao reconhecer essa situação, Honneth apresenta pretensões mais elevadas e avança em relação à questão, pois, "Diferentemente da crítica interna simples, que Kaupinnen remonta ao modelo clássico da critica à ideologia e que apelaria à contradição entre normas expressas e prática efetivas, a crítica interna reconstrutiva [nos moldes de Honneth] apelaria à contradição entre normas incorporadas nas práticas efetivas e essas práticas mesmas".

No caso desse tipo de elaboração, no entanto, está presente um segundo desafio, a saber, o da superação de uma forma comunitarista de crítica (a crítica fraca ou contextual). Tal aspecto se interpõe, já que, para dar conta das pretensões de universalidade de sua reconstrução normativa, seria necessário a Axel Honneth, por exemplo, revisar os elementos de sua argumentação em Luta por reconhecimento (HONNETH, 2003), na qual a concepção de autorrealização alimentada pelos indivíduos em suas práticas era descrita como sempre relacionada a um conjunto de valores contextuais ou uma visão particular de mundo e de vida 
boa (ou seja, o reconhecimento estaria atrelado a uma perspectiva intersubjetiva de identidade pessoal). Na visão de autores como Kaupinnen (2002), o não enfrentamento de tal aspecto poria sob risco, portanto, o próprio alcance da empreitada reconstrutiva a que Honneth se propõe. Reconhecendo tal fragilidade, o autor procura apresentar os aspectos das relações de reconhecimento em outros termos e, particularmente em seu "Direito a liberdade",

[...] a 'conexão' que Honneth irá buscar agora não será mais 'entre a experiência de reconhecimento e a relação consigo próprio', dada por uma 'estrutura intersubjetiva da identidade pessoal' fundada em uma antropologia filosófico-naturalista, mas entre 'as expectativas subjetivas de reconhecimento e os discursos de justificação praticados socialmente' (CRISSIUMA, 2013, p. 77).

Assim, Honneth (2015) tem condições não apenas de apontar a existência de um campo de imanência normativa do social, mas de destacar a existência de valores de referência que servem para a provisão da integração social, constituindo-se em critérios que, endossados pelo reconhecimento generalizado, figuram como balizadores da ação individual. Para Caux (2015), é exatamente esse elemento o que permite ao autor alemão superar um modelo construtivista que, ao elaborar de modo prévio e apartado os procedimentos racionais que serão aplicados posteriormente a uma realidade que lhes é heterogênea, tendia a separar idealidade e efetividade. Para Honneth (2015), portanto, a "reconstrução normativa" deve ser entendida como um processo reconstrutor dos próprios desdobramentos históricos das instituições sociais, pois somente desse modo se faria possível uma análise do grau de compreensão da liberdade institucionalizada e o alcance de sua realização. Nessa esteira, seu modelo de crítica reconstrutiva ou imanente, afastando-se de princípios últimos ou externos aos contextos efetivos, assume como referência também os valores orientadores de ação na estrutura das práticas sociais.

Para além, o salto alcançado por Axel Honneth dá-se pela compreensão de que cabe à tarefa de uma reconstrução normativa o papel de uma apresentação que nela própria desvela pontos de vista normativos. Ou seja, "[...] a forma de exposição deve servir à explicitação de uma melhor autocompreensão normativa das esferas reconstruídas" (CAUX, 2015, p. 93). Quer dizer:

[...] namedida em quea esses valores enormaséimputado um excedente semântico de validade que impele transcendentalmente as relações de reconhecimento em direção a uma crescente universalização, no sentido da individualização e da inclusão de mais formas de vida sancionadas socialmente, sua reconstrução mesma, entendida como a explicitação de normas já existentes de forma implícita, deve conter um elemento crítico: a reconstrução assume o papel de tensionar o excedente de validade das normas reconstruídas e oferecer, num diálogo com os atores sociais ordinários, insumos de justificação das pretensões levantadas no conflito social. Ela pode reatar, assim, o vínculo com a crítica, desde que se entenda, como interpreta Volker Heins, que 'crítica não é instância direcionadora, mas força impulsora e resseguro simbólico para atores sociais que já são eles mesmo críticos' (HEINS, 2014, p. 143-144) (CAUX, 2015, p. 87).

Honneth (2015) ainda destaca a ideia de que uma crítica imanente não deve limitarse à explicitação reconstrutiva de instâncias de eticidade já existentes, mas deve, de forma concomitante, permitir sua crítica a partir dos valores a cada tempo. Assim, corresponde a uma crítica social apontada numa dupla direção: por um lado, deve incidir nas práticas desenvolvidas a partir dos valores institucionalmente encarnados; e, por outro, alcança o que se refere ao próprio grau de insuficiência ou patologia dos valores sociais que estruturam as instituições. 


\section{CONSIDERAÇÕES FINAIS}

Conforme vimos descrevendo, as tentativas de superação do quadro adverso acerca da relação entre pesquisa/produção acadêmica e intervenção pedagógica têm passado também pela apropriação de outros modos de se compreender e realizar a pesquisa pedagógica. Entre as alternativas promissoras que se anunciam, destacamos os emergentes estudos nos/dos/ com os cotidianos, que, de forma mais radical, apelam para uma desinvisibilização dos produtos das práticas cotidianas (ao apostar na necessidade de uma maior valorização do cotidiano e dos saberes que nele se produzem). Nesse sentido, ao longo de nossa argumentação, enfatizamos positivamente a presença de alguns pressupostos desta corrente investigativa que, acreditamos, se mostram potentes para a qualificação da pesquisa pedagógica em EF.

No entanto, a despeito disso, também situamos nossa preocupação em relação ao fato de que, da forma como está apresentada, tal produção teria como consequência a impossibilidade de construção de um modelo de "crítica forte" no âmbito da teorização pedagógica (aspecto decorrente dos fundamentos teóricos que subsidiam tal modelo de pesquisa, majoritariamente, situados nas perspectivas de análise pós-modernas). Desse modo, ao mesmo tempo em que compartilhamos com as pesquisas nos/dos/com os cotidianos do diagnóstico de que "há mais no cotidiano do que a 'pesquisa clássica' tem sido capaz de mostrar" (o que demanda mudanças nos modos de apropriação e análise desse lugar), temos olhado com receio as práticas de supervalorização desse mesmo cotidiano (porque "possíveis" nas adversidades cotidianas, todos os esforços e produções do chão da escola são necessariamente bons?). Situação evidente, particularmente, em decorrência de uma compreensão que atribui à dimensão de auto-organização do cotidiano um caráter também autorreferenciado.

No sentido de reconhecer uma lógica própria das práticas cotidianas, sem cair na armadilha de reduzir o estabelecimento de seus critérios justificadores somente às demandas mais imediatas que se lhe apresentam, é que o diálogo com a noção de reconstrução normativa, nos termos de Honneth (2015), nos parece profícuo. Ou seja, a partir dessa breve apresentação de alguns argumentos de sua teorização, acreditamos ter podido conotar a possibilidade de realização de estudos acerca da intervenção pedagógica em EF que, mesmo assumindo a necessidade de distanciar-se cada vez mais dos questionáveis modelos prescritivos universais, ainda mantenha espaço para o exercício da crítica, agora, na forma de uma "crítica imanente".

Desse modo, acreditamos que tal referencial honnethiano se mostra potente por duas vias distintas: a primeira, em acordo com o que interpretamos positivamente nos estudos nos/dos/com os cotidianos, ao permitir elementos auxiliadores de uma interpretação das maneiras específicas como as práticas escolares se desenvolvem (de forma a identificar suas "realizações normativas" e não negar os potenciais emancipatórios nelas contidos); ao passo que a segunda, numa perspectiva que extrapola o escopo de análise das narrativas nos/dos/ com os cotidianos, resgata a necessidade de também visualizarmos/buscarmos na "facticidade empírica" do cotidiano o empreendimento de ações, sejam individuais sejam institucionais, cujo sentido Ihe confira unidade em relação a um projeto institucional público e mais amplo de Educação (Física).

Finalizamos este texto reconhecendo o fato de que a pretensão de uma tarefa como a que explicitamos, ainda que referenciada numa perspectiva normativa ampla como a de Honneth (2015), carece de ser acompanhada da demarcação de alguns pontos de partida. Quer dizer, 
ao discutirmos a instituição escolar, dada a disputa entre diferentes discursos legitimadores de sua função social, far-se-á sempre necessária a explicitação/construção de um referente normativo que considere como possível o seu status de provisoriedade. Essa é, portanto, uma tarefa que deve pautar nossos esforços ulteriores. Para tanto, ao pensarmos no contexto educacional brasileiro, em que a educação escolarizada, entre outras, tem a função potencial de equalizar as desigualdades fundantes que marcam nosso quadro social (mormente, no que diz respeito ao exercício democrático), vislumbramos a acepção de um modelo escolar que tenha como télos o resgate de uma dimensão "pública" de educação. No caso da instituição social escola, portanto, seria também este sentido público aquilo que configuraria o ponto referencial para a construção de um pressuposto normativo fundamentador. Por fim, há de se ressaltar que falar de uma educação "pública" significa que o acesso aos bens culturais, ainda fundamentais num projeto de educação escolarizada, deve ser concebido numa perspectiva que vai além do suprimento imediato das necessidades, mas que possibilite condições para a criação e livre gestão do mundo.

\section{REFERÊNCIAS}

ALVES, Nilda. Decifrando o pergaminho: o cotidiano das escolas nas lógicas das redes cotidianas. In: OLIVEIRA, I.B.; ALVES, N. (Org.). Pesquisa no/do cotidiano das escolas: sobre redes de saberes. Rio de Janeiro: DP\&A, 2001. p. 34-59.

ALVES, Nilda. Sobre redes de conhecimentos e currículos em redes. Revista de Educação, v. 1, n. 122, p. 94-107, 2002.

ALVES, Nilda. Sobre movimentos das pesquisas nos/dos/com os cotidianos. Revista Teias, v. 4, p.1-8, 2007.

BRACHT, Valter et al. A Educação Física Escolar como tema da produção do conhecimento nos periódicos da área no Brasil (1980-2010): parte II. Movimento, v. 18, n. 2, p. 11-37, 2012.

CAUX, Luiz Philipe. A reconstrução normativa como método em Honneth. PERI, v. 7, n. 2, p. 83-98, 2015.

CERTEAU, Michel de. Artes de fazer: a invenção do cotidiano. Petrópolis: Vozes,1994.

CRISSIUMA, Ricardo. Trocando o jovem pelo velho: Axel Honneth leitor de Hegel. In: A teoria crítica de Axel Honneth: reconhecimento, liberdade e justiça. São Paulo: Saraiva, 2013. p. 55-81.

FALCÃO, Júlia Miranda et al. Saberes compartilhados no ensino de jogos e brincadeiras: maneiras/artes de fazer na Educação Física. Revista brasileira de Ciências do Esporte, v. 34, n. 3, p. 615-631, 2012.

FERRAÇO, Carlos Eduardo. Pesquisa com o cotidiano. Educação \& Sociedade, v. 28, n. 98, p. 73-95, 2007.

FERRAÇO, Carlos Eduardo. A pesquisa em educação no/do/com o cotidiano das escolas. In: OLIVEIRA, Inês Barbosa de (Org.).Aprendizagens cotidianas com a pesquisa: novas reflexões em pesquisa nos/dos/com os cotidianos. Petrópolis: DP et Alii, 2008. p. 23-33. 
FERRAÇO, Carlos Eduardo; PEREZ, Carmem Lúcia Vidal; OLIVEIRA, Inês Barbosa. Diferentes abordagens, temas e modos de ser da pesquisa nos/dos/com os cotidianos. In: OLIVEIRA, Inês Barbosa de (Org.).Aprendizagens cotidianas com a pesquisa: novas reflexões em pesquisa nos/dos/com os cotidianos. Petrópolis: DP et Alii, 2008. p. 15-22.

GAMBAROTTA, Emiliano Mátias. Hacia una teoría crítica reflexiva: Max Horkheimer, Theodor W. Adorno y Pierre Bourdieu. Buenos Aires: Prometeo Libros, 2014.

GONZÁLEZ, Fernando Jaime; FENSTERSEIFER, Paulo Evaldo. Entre o "não mais" e o "ainda não": pensando saídas do não-lugar da EF escolar I. Cadernos de Formação RBCE, v. 1, n. 1, p. 9-24, 2009.

HONNETH, Axel. Luta por reconhecimento: a gramática moral dos conflitos sociais. São Paulo: Ed.34, 2003.

HONNETH, Axel. Patologías de la razón. Buenos Aires: Katz Editores, 2009.

HONNETH, Axel. $O$ direito da liberdade. Trad. de Saulo Krieger. São Paulo: Martins Fontes, 2015.

KAUPPINEN, Antti. Reason, recognition, and internal critique. Inquiry, v. 45, n. 4, p. 479-498, 2002.

NUNES, Kezia Rodrigues; FERREIRA NETO, Amarílio. Os currículos da Educação Física na educação infantil em Vitória, ES (1991-2007). Revista Diálogo Educacional, v. 12, n. 36, 2012.

OLIVEIRA, Inês Barbosa de. Currículos praticados, emancipação social e democracia no cotidiano da escola: um relato de pesquisa. In: FERRAÇO, Carlos Eduardo; PEREZ, Carmem Lucia Vidal; OLIVEIRA, Inês Barbosa de. Aprendizagens cotidianas com a pesquisa: novas reflexões em pesquisa nos/dos/com os cotidianos das escolas. Petrópolis: DP et Alii, 2008. p. 105-120.

OLIVEIRA, Inês Barbosa de; SGARBI, Paulo. Estudos do cotidiano e educação. Belo Horizonte: Autêntica, 2008.

SANTOS, Wagner; MAXIMIANO, Francine de Lima. Avaliação na educação física escolar: singularidades e diferenciações de um componente curricular. Revista Brasileira de Ciências do Esporte, v. 35, n. 4, p. 883-896, 2013.

SGARBI, Paulo. Epistemologia e as lógicas cotidianas. Aprendizagens cotidianas com a pesquisa: novas reflexões em pesquisa nos/dos/com os cotidianos. Petrópolis: DP et Alii, 2008. p. 159-177.

TABORDA DE OLIVEIRA, Marcus Aurélio. A Revista Brasileira de Educação Física e Desporte (1968-1984) e a experiência cotidiana de professores da Rede Municipal de Ensino de Curitiba: entre a adesão e a resistência. 2001. 397 f. Tese (Doutorado em História e Filosofia da Educação) - Programa de Estudos Pós-Graduados em Educação: História, Política e Sociedade, São Paulo, 2001.

Apoio financeiro:

Católica de Vitória - Centro Universitário; Programa de Pós-Graduação em Educação Física (PPGEF-UFES) 